\title{
The 3-dimensional cardiac hype cycle
}

\author{
David P. Bichell, MD
}

\author{
From the Division of Pediatric Cardiac Surgery, Vanderbilt University Medical Center, Nashville, Tenn. \\ Disclosures: Author has nothing to disclose with regard to commercial support. \\ Received for publication March 25, 2018; accepted for publication March 28, 2018. \\ Address for reprints: David P. Bichell, MD, William S. Stoney, Jr, Monroe Carell, Jr, Children's Hospital, Van- \\ derbilt University Medical Center, 5247 Doctors' Office Tower, 2200 Children's Way, Nashville, TN 37232 \\ 9292 (E-mail: david.bichell@vanderbilt.edu). \\ J Thorac Cardiovasc Surg 2018; 156:e125 \\ $0022-5223 / \$ 36.00$ \\ Copyright (C 2018 Published by Elsevier Inc. on behalf of The American Association for Thoracic Surgery \\ https://doi.org/10.1016/j.jtcvs.2018.03.143
}

The maturational timeline of any new technology, according to Gartner's "hype cycle," follows a predictable sequence. ${ }^{1}$ The sequence starts with the highly visible "peak of inflated expectations" phase, followed by a lower profile "slope of enlightenment," when hyperbole wanes and the technology's true capabilities are refined, and it ultimately settles at a less glamorous "plateau of utility," where the innovation finds its honest and valued place.

The first computed tomographic (CT) scan images appeared in the 1970s. ${ }^{2}$ Multislice scanners, doubling in the number of detector rows and image resolution every 2 years through the early 2000s, became at each step capable of producing more stunning and detailed 3-dimensional (3D) renderings of hidden parts of the human body. Stereolithography, or 3D printing, was developed in the 1980s. It also enjoyed explosive media popularity in the first decade of the 2000s, as on-demand 3D printing in various materials became widely available. Advances in 3D printing and CT imagery first combined in 2006 to build neonatal congenital heart defect models from CT image dot clouds. ${ }^{3}$

An internet search for the sensationalistic phrase, "3D printing saved my life!" turns up medical center promotional newsletter headlines and glossy ads with poster children holding up plastic heart models, touting formerly impossible operations made possible by preoperative planning around a plastic model. As this spectacular 3D medical imaging has blossomed, capturing the attention of the public and of publicists, the images and their transformative promises have come to adorn web sites, journal articles, and slide presentations. Plastic 3D models that you can hold in your hand are available for both practical and fanciful purposes. On the basis of the density of internet posts, the peak of exaggerated expectations for advanced 3D cardiac imaging seems to have been reached around 2015 to 2016. The obligate first phase of the hype cycle for $3 \mathrm{D}$ $\mathrm{CT}$ and $3 \mathrm{D}$ cardiac printing has been realized. The progression from wow to utility follows.

In this issue of the Journal, Thomas and colleagues ${ }^{4}$ describe sophisticated cardiac imaging that so perfectly defined the nature and location of a rare fistula between the right pulmonary artery and left atrium that it could be sier solutions.

\section{References} 2008. 2018;156:e121-3.

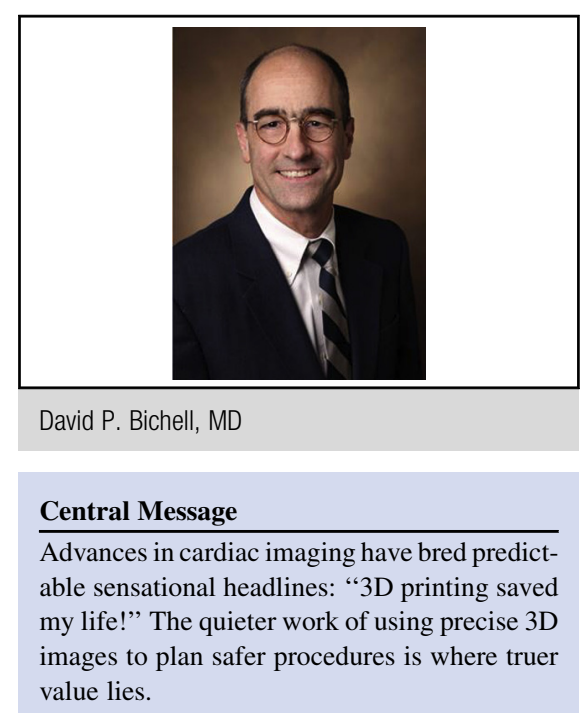

See Article page e121.

used to direct with accuracy an approach to fistula ligation that was made with precision, minimal incision, confidence, and safety. An exploratory thoracotomy or sternotomy would have been necessary were it not for the sophistication of 3D heart imagery, pinpointing the isthmus of the fistula and the geometry that permitted its simple staple division. Sophisticated 3D imagery did not make a heretofore impossible operation possible, but it did lend the precision and confidence that allowed the procedure to be less invasive, more precise, and more practical.

Beyond the peak of inflated expectations and on our way to the more enduring business of defining the plateau of utility, Thomas and colleagues ${ }^{4}$ contribute a light bulb to the slope of enlightenment. News of 3D congenital cardiac imaging decorates fewer sensational headlines now, but it continues to inform such thoughtful and directed treatment strategies, conferring safety and certainty on formerly mes-

1. Fenn J, Raskino M. Mastering the Hype Cycle: How to Choose the Right Innovation at the Right Time. Boston: Harvard Business School Publishing;

2. Hounsfield GN. Computerized transverse axial scanning (tomography): part I. Description of system. 1973. Br J Radiol. 1995;68:H166-72.

3. Greil GF, Wolf I, Kuettner A, Fenchel M, Miller S, Martirosian P, et al. Stereolithographic reproduction of complex cardiac morphology based on high spatial resolution imaging. Clin Res Cardiol. 2007;96:176-85.

4. Thomas PA, Soulatges C, Ovaert C, Mace L. Congenital right pulmonary artery to left atrial fistula: Elective videothoracoscopic stapling. J Thorac Cardiovasc Surg. 